\title{
AS POLÍTICAS EDUCACIONAIS E O PROCESSO DE FECHAMENTO DAS ESCOLAS DO CAMPO NO MUNICÍPIO DE CASA NOVA - BA
}

\author{
LAS POLITICAS EDUCACIONALES Y LO PROCESO DE CIERRE DE LAS ESCUELAS \\ DEL CAMPO EN EL MUNICIPIO DE CASA NOVA - BA
}

\section{EDUCATIONAL POLICIES AND THE CLOSING PROCESS OF RURAL SCHOOLS IN THE CITY OF CASA NOVA - BA}

DOI: http://doi.org/10.9771/gmed.v13i2.43555

\author{
Franciel Coelho Luz de Amorim \\ Maria Jorge dos Santos Leite ${ }^{2}$
}

\begin{abstract}
Resumo: O objetivo desse artigo é mapear as principais políticas educacionais e suas implicações à educação no campo. Abordamos o processo de fechamento das escolas do campo no município de Casa Nova - BA, considerando este um dos principais efeitos das políticas educacionais do Estado brasileiro direcionadas ao campo: as escolas foram reduzidas em quase $50 \%$, de 2010 a 2018. A educação camponesa passou por um intenso processo de fechamento, o qual foi desencadeado a partir da política de transporte escolar, ainda na década de 1990, transformando-se, não em uma política propriamente de educação, mas em uma política de transporte (negócio), cujas velhas práticas locais e interesses privados sobrepõem-se à premissa da educação pública, gratuita e de qualidade. A análise em estudo ancora-se no materialismo histórico-dialético.
\end{abstract}

Palavras-chave: Políticas educacionais. Fechamento das escolas do campo. Transporte escolar. Casa Nova - BA.

Resumen: El propósito de este artículo es mapear las principales políticas educativas y sus implicaciones para la educación en el campo. Abordamos el proceso de cierre de escuelas rurales en el municipio de Casa Nova - BA, considerando este uno de los principales efectos de las políticas educativas del Estado brasileño dirigidas al campo: las escuelas se redujeron en casi un 50\%, de 2010 a 2018. La educación campesina atravesó un intenso proceso de cierre, que fue desencadenado por la política de transporte escolar, aún en la década de 1990, convirtiéndose, no en una política de educación, sino en una política de transporte (empresarial), cuyas antiguas prácticas locales e intereses privados se traslapan con la premisa de una educación pública, gratuita y de calidad. El análisis en estudio está anclado en el materialismo histórico-dialéctico.

Palabras-clave: Políticas educativas. Cierre de escuelas rurales. Transporte escolar. Casa Nova - BA

Abstract: The goal of this article is to map the main educational policies and their implications on rural education. It approaches the process of shutdown of rural schools in the city of Casa Nova, Bahia, considering that's one of the main effects of the educational policies of the Brazilian State for the rural areas: the schools were reduced by about half between the period of 2010 to 2018. Rural education suffered an intense process of shutdowns, which began after the school transportation policies, still in the 1990s, became, not a proper educational policy, but a transportation policy (a business), which old local practices and private interests superposed the premise of public, free and quality education. Its analysis in question is anchored on the historical-dialectical materialism.

Keywords: Educational policies. Rural schools shutdown. School transportation. Casa Nova - Bahia. 


\section{Introdução}

Na América Latina e no Brasil, em especial, ocorreu com o término da Segunda Guerra Mundial (1939-1945) o predomínio da interferência dos Estados Unidos - EUA, fazendo esse continente refém da hegemonia externa exercida pelos norte-americanos, especialmente no campo tanto da economia quanto da política. Essa hegemonia se fortaleceu e se ampliou ao longo do tempo, sobretudo pela criação e atuação de agências e órgãos controlados pelo capital financeiro internacional como o Fundo Monetário Internacional (FMI), Banco Mundial (Bird), Organização Mundial do Comércio (OMC), Organização das nações Unidas (ONU), Organização do Tratado do Atlântico Norte (Otan) etc.

Dentre tais organismos, destaca-se o chamado Banco Mundial - BM. Este que assinala duas organizações: o Banco Internacional de Reconstrução e Desenvolvimento (Bird) e a Associação Internacional de Desenvolvimento (AID) que conformam, por sua vez, o Grupo Banco Mundial (GBM). Tal organismo é entendido como "[...] um conjunto de entidades cuja atuação em larga medida se articula e se concatena”. (PEREIRA, 2014, p.20), o qual se destaca na propagação e controle do capitalismo pelo globo terrestre, em especial nos países da América Latina. "Isto porque o BM é um ator político, intelectual e financeiro, devido à sua condição absolutamente singular de emprestador, formulador e articulador de políticas [...]" (PEREIRA, 2014, p.20), especialmente, no que se refere às áreas da agricultura e da educação.

No que diz respeito à educação, as propostas do Banco Mundial tiveram como ênfase a educação básica, a descentralização da gestão e a reorganização dos sistemas escolares, tal como a centralização da avaliação educacional por meio da criação de instrumentos padronizados de avaliação. Por isso, para Souza (2014, p. 160), "uma das principais ações resultantes da descentralização foi a municipalização da educação, processo antidemocrático que visa a desobrigação das outras esferas administrativas para com a educação básica, tornando-a ainda mais precária”.

Para atender a essas reformas, acima mencionadas, foi criado, desde o governo de Fernando Henrique Cardoso (FHC), o Fundo de Manutenção e Desenvolvimento do Ensino Fundamental e Valorização do Magistério (FUNDEF) - Lei n.9424/96 (BRASIL, 1996). Essa Lei foi revogada por meio da Lei n. 11.494 de 20 de junho de 2007, que criou o Fundo de Manutenção e Desenvolvimento da Educação Básica e de Valorização dos Profissionais da Educação (FUNDEB), que abarca toda a estrutura e organização da educação básica, representando, sobretudo, uma acentuada descentralização na gestão educacional, transferindo-a aos Municípios e aos Estados.

A referida descentralização da gestão educacional, acentuada a partir do FUNDEB, representou, sobretudo, os seguintes aspectos: a) maior responsabilidade das instituições pelo rendimento escolar de seus alunos; b) resultados mensurados mediante parâmetros externos centralizadores de avaliação (IDEB, Prova Brasil, etc.); c) racionalização dos recursos públicos na educação e incentivo por captação de recursos por meio de parcerias privadas, impulsionando os projetos de privatização da educação. Essas características podem ser evidenciadas na própria Lei de Diretrizes e Bases (Lei n. 9394/96) (BRASIL, 1996), que proporcionou, com a descentralização do sistema e da gestão, “[...] a forte centralização na 
avaliação, entendida como controle de resultados e fixação de padrões de desempenho" (MOTA JUNIOR; MAUÉS, 2014, p.1140) conforme as exigências do Banco Mundial.

No que se refere ao financiamento, entrou em destaque, mais uma vez, inclusive para toda a América Latina, o predomínio do Banco Mundial que iniciou um programa abrangente de educação, no Brasil, recebendo o nome de - Projeto Fundo de Fortalecimento da Escola (FUNDESCOLA), sendo que boa parte de suas ações foram direcionadas à educação camponesa, principalmente, nas regiões Norte e Nordeste, cujos objetivos centrais eram:

[...] promover a eficácia, eficiência e eqüidade no ensino fundamental público das regiões Norte, Nordeste e Centro-Oeste, por meio da oferta de serviços, produtos e assistência técnico-financeira inovadores e de qualidade, que focalizam o processo de ensino-aprendizagem e as práticas gerenciais das escolas e secretarias de Educação. (BRASIL, 2007, grifo nosso).

Como se nota, os objetivos dos pacotes de investimentos focalizavam as práticas "gerenciais", ou seja, de controle, de domínio das instituições e de seus sujeitos mediante o modelo de racionalidade taylorista que visa, no caso da educação, dividir as tarefas (decisão e execução) e o trabalho no interior da escola. "O modelo gerencial e burocrático se fundamenta nos modelos de planejamento estratégico e 'qualidade total"'. (SOUZA, 2014, p. 176). É tanto que o MEC não fala, em nenhum momento, em práticas democráticas, práticas coletivas, pensadas e construídas, por exemplo, pelos próprios sujeitos envolvidos no processo educativo (professores, alunos, pais, comunidade), mas, sim, no absorvimento dos referidos pacotes de serviços, produtos e assistência técnico-financeira.

Deste modo, nos pacotes de investimentos do Fundescola/Banco Mundial, alguns programas criados ganharam destaque nas referidas regiões, assim como no município em estudo, dentre eles: o Projeto de Adequação dos Prédios Escolares (PAPE), o Caminho da Escola e o Programa Nacional de Apoio ao Transporte Escolar (PNATE). O PAPE significou, pois, um grande impacto na educação camponesa, sobretudo pela proposta de construção de "escolas polos", resultando no fechamento das escolas rurais, em geral multisseriadas. Sendo assim, em Casa Nova - BA, ao passarmos pelas estradas de terra que ligam as comunidades rurais do município, encontramos dezenas delas fechadas, embora continue havendo, dezenas dessas escolas no município em funcionamento. Essa política de fechamento escolar foi massiva em todo o Norte e Nordeste do país para atender aos ditames do imperialismo (Banco Mundial). Deste modo, destaca-se que:

O plano de fechamento das escolas se deu a partir da década de 1990, quando as prefeituras foram induzidas pelo MEC a fechá-las, com a promessa de financiamento do transporte escolar. Foi um verdadeiro cavalo de tróia, pois, [...] o repasse de recursos pelo MEC, provenientes dos programas financiados pelo Banco Mundial, é irrisório frente à demanda de transporte existente nos municípios. (SOUZA, 2014, p.170).

A assertiva de Souza (2014), sobre o fechamento das escolas do campo na Amazônia ocidental, especificamente nos municípios rondonienses, resume o cenário que também identificamos em Casa Nova, no Estado da Bahia. O deliberado processo de fechamento das escolas do campo se acentuou em detrimento de uma política de transporte escolar. No entanto, os recursos provenientes do PNATE, 
programa do MEC/Banco Mundial para financiar o transporte escolar são irrisórios diante da demanda criada no município após o fechamento das escolas, transformando a política de educação em uma lógica mercadológica de transporte, conforme abordaremos adiante. A isso segue associado, também, por outro lado, o agravo da progressiva expansão do agronegócio frutícola, esse que consideramos um latifúndio de novo tipo.

Nesse sentido, o imperialismo, por meio do Banco Mundial, passou a interferir na educação brasileira, a partir da década de 1990, em uma proporção jamais vista, assim como demonstra uma avaliação realizada e publicada pelo próprio Banco quanto ao período dos governos FHC e Lula. O Banco Mundial proferia nessa época, "a educação primária e secundária é cada vez mais importante: nos exercícios de 1990 a 1994 lhe correspondeu a metade de todos os empréstimos para educação"3 (BANCO MUNDIAL, 1996, p. 16, tradução nossa).

Embora não seja nossa intenção realizar uma análise profunda das ações, políticas e programas educacionais do Banco Mundial, é importante destacarmos que no Brasil, conforme Souza (2014), quase toda a política educacional atual é, pois, fruto de uma influência do Banco Mundial, seja de maneira direta ou indireta. Para tanto, considerando essas relações gerais e especificas, que se interagem entorno das políticas educacionais até o resultante fechamento das escolas do campo, adotamos o materialismo histórico-dialético na análise de tal processo. A aplicação deste método, especificamente, a lei da contradição (unidade dos contrários), como lei única-fundamental de todos os fenômenos, possibilita-nos compreender as múltiplas determinações que concatenam e fazem os fatos existirem. A aplicação da dialética materialista refere-se à compreensão de que existe relação/interação em todos os fenômenos, ou seja, a educação é determinada pela sociedade, na forma em que se estruturam as relações sociais e econômicas.

O município de Casa Nova, na Bahia, é o nosso espaço de estudo. Ele integra uma microrregião do Estado baiano pertencente à mesorregião do Vale São-Franciscano, sendo composta, além de Casa Nova, por Juazeiro, Sobradinho, Remanso, Sento Sé, Curaçá, Pilão Arcado e Campo Alegre de Lourdes. (BRASIL, 2015). A maioria deles possuem históricos de deslocamento de sua população em consequência da construção da Hidrelétrica de Sobradinho que alagou grande parte de seus territórios na década de 1970, sendo que, atualmente, os municípios convivem com a tônica expansionista do latifúndio de novo tipo (por sua aparência de moderno), cunhando-se o termo de agronegócio frutícola.

Quanto à coleta de dados, utilizamos de dois procedimentos básicos: a análise de documentos e a pesquisa participante, tendo a observação e a entrevista como os instrumentos básicos.

A análise documental, conforme definida por Gil (2002, p.46), teve por base os “[...] documentos outros que não aqueles localizados em bibliotecas", mas nas secretarias de educação, na legislação educacional ou mesmo nas publicações e dados educacionais oficiais, a exemplo do Censo Educacional do Ministério da Educação - MEC.

A pesquisa participante, como um dos métodos utilizados nessa investigação, está associada à análise documental por meio de dois instrumentos básicos: a observação e a entrevista. 
Utilizamos da observação como instrumento de pesquisa, a qual se tornou necessária, sobretudo, pela nossa atuação docente no município (tornando-se partícipe do fenômeno estudado), de setembro de 2015 a maio de 2018, na condição de professor contratado da rede estadual da Bahia. Entendemos que a observação, por estar agrupada e sistematizada à intencionalidade que conduzem os objetivos do estudo, contribuiu para a compreensão do fenômeno em estudo. Por isso, ao observarmos o ambiente, os sujeitos sociais e sua relação com a escola, registramos sempre os fatos e situações observadas em um caderno de campo.

Já para as entrevistas, optamos pela modalidade de entrevista semiestruturada, individual e aplicada com educadores e membros-gestores de políticas educacionais do referido município. A escolha dessa modalidade de entrevista reside no fato de se tratar de um instrumento mais flexível, o qual nos permitiu realizar os ajustes necessários, primando pela interação (verbal e não verbal) entre pesquisadorentrevistador, na busca por responder aos objetivos da pesquisa a partir do próprio ato de entrevistar. O roteiro utilizado nas entrevistas seguiu-se baseado nos temas levantados nos objetivos, no referencial teórico, na realidade educacional do município e nos aspectos fundamentais do estudo já detectados na pesquisa documental a partir dos dados do Censo Educacional do MEC.

Seguindo tais trilhas metodológicas, detectamos que, no município em estudo, as escolas do campo foram reduzidas em cerca de 50\% em um período de nove anos (2010 a 2018), conforme conseguimos mapear com base nos dados documentais obtidos por meio dos Censos Educacionais do MEC e confirmados tanto pela observação participante como nas entrevistas realizadas com educadores e membros-gestores de políticas educacionais do município. Acompanhemos, então, a análise desse processo de fechamento das escolas do campo em Casa Nova - BA.

\section{As políticas educacionais e suas implicações no fechamento das escolas do campo}

No Brasil existe, atualmente em curso, a destruição de vários direitos historicamente conquistados. Um desses processos é o contínuo e progressivo fechamento das escolas do campo, retirando de muitas populações camponesas o direito à escola. Processo esse que foi analisado, por exemplo, por Taffarel e Munarim (2015, p.46), ao concluírem que, entre 2005 a 2015, "o número de escolas do campo brasileiras fechadas é enorme. As escolas foram reduzidas em 31,46\%, ou seja, 32.512 unidades foram fechadas." Segundo os autores, somente em 2014 mais de 4 mil escolas foram fechadas no Brasil, “quase absolutamente todas no campo.” (TAFFAREL; MUNARIM, 2015, p.47).

O crime deliberado de fechamento de milhares de escolas do campo, praticado pelos governos Lula e Dilma, aprofundados por Temer e agora por Bolsonaro, é um reflexo da política de esvaziamento do campo, integrada à estratégia expansionista do imperialismo, ao impulsionar o agronegócio como um latifúndio de novo tipo, destacando-se sua expansão em Casa Nova - BA, o qual interfere no processo educacional dos jovens, ao desistirem da escola para se tornarem trabalhadores, explorados e vulneráveis nas entranhas do latifúndio. Essas são características, não exclusivas deste 
município e desta região, mas que se encontram também em outras regiões do país. (JUNQUEIRA, 2014; 2015). O latifúndio é um aspecto vivo e intacto da herança colonial, o qual traz imensas implicações à educação camponesa. (JESUS; BEZERRA, 2013).

O município de Casa Nova - BA4, atualmente, possui uma estimativa do Instituto Brasileiro de Geografia e Estatística (IBGE) de mais de 70 mil habitantes, sendo que o processo de centralização das escolas de Ensino Médio é enorme, conforme analisaremos mais adiante. Segundo ainda consta no panorama de cidades do censo demográfico do IBGE (2010), quase $50 \%$ da população do município é residente na "zona rural”. O município possui Índice de Desenvolvimento Humano - IDH de 0,57, bem abaixo do índice do Estado da Bahia $(0,66)$ e bastante inferior com relação ao do Brasil $(0,727)$. Fica assim, indicado pelo próprio dado oficial, a condição de decadência econômica dessa população, grande parte trabalhadora do agronegócio e que convive diariamente com o verde da irrigação, contracenando com a propaganda ideológica do "Agro é pop" na TV.

Nos dados levantados, por meio dos Censos Educacionais do Ministério da Educação, é possível observarmos um processo de disparidade do registro de matrículas dos níveis de educação Fundamental (I e II) em relação ao Ensino Médio. É sabido, pois, que o Ensino Fundamental (I e II) possui nove anos de duração, enquanto o Ensino Médio possui apenas três anos. No entanto, mesmo havendo uma redução de 2017 em relação a 2005, devido ao aumento de matrículas no Ensino Médio e a consequente diminuição no Ensino Fundamental, percebe-se uma imensa disparidade de acesso entre os dois níveis de ensino.

Gráfico 1: Matrículas por nível escolar em Casa Nova - BA (2005 - 2017)

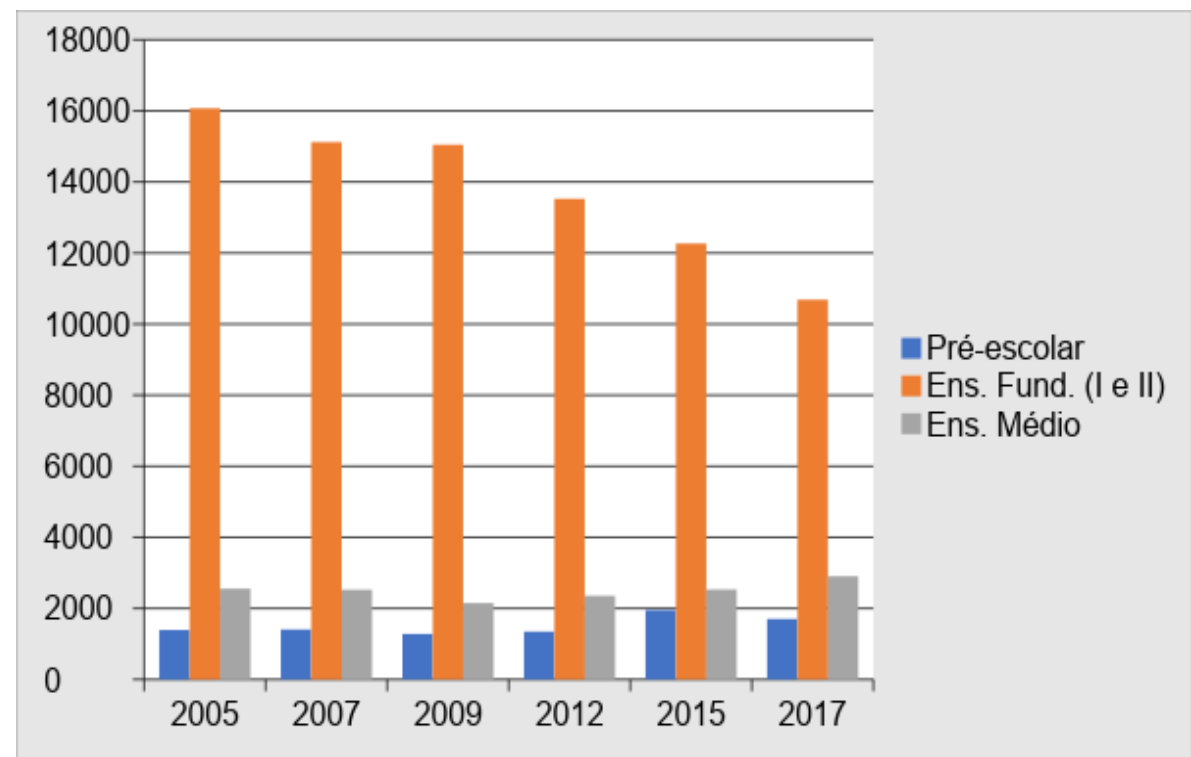

Fonte: Censo Educacional do INEP/MEC (2017); Panorama do IBGE (2010). (Elaboração: Autores, 2018).

A partir dos dados levantados, constantes no Gráfico 1, podemos tecer as seguintes considerações: no ano de 2005, haviam mais de dezesseis mil matrículas no Ensino Fundamental e, apenas, pouco mais de duas mil e quinhentas matrículas no Ensino Médio. Se for considerada essa mesma 
comparação em relação ao último ano levantado (2017), é possível percebermos o seguinte: no Ensino Fundamental são, atualmente, conforme o Censo INEP/MEC do ano de 2017, pouco mais de dez mil e seiscentas matrículas, enquanto no Ensino Médio foram duas mil e novecentas matrículas. Ou seja, percentualmente, as matrículas do Ensino Fundamental decresceram 33,4\% (5.380 matrículas) enquanto as do Ensino Médio cresceram apenas 13,7\% (350 matrículas).

Por que mais de cinco mil alunos, precisamente 5.030 alunos (19,7\%), verificados na disparidade de acesso do Ensino Fundamental para o Médio, não conseguiram acessar, no decorrer dos doze anos (2005-2012), o Ensino Médio?

Decidimos, então, buscar as razões desse processo de disparidade a partir de dois aspectos fundamentais: 1) a comparação dos registros de matrículas no Censo Educacional de 2017 entre as escolas urbanas e as escolas do campo; e, 2) a verificação e conseguinte comparação do número de escolas existentes na zona urbana e na zona rural, em seus diferentes níveis e sistemas de ensino.

Com relação ao primeiro aspecto, levantamos e reunimos os dados das Matrículas escolares iniciais do município de Casa Nova (Tabela 1) no Censo Escolar 2017.

Tabela 1: Matrículas iniciais no município de Casa Nova - BA (2017)

\begin{tabular}{|c|c|c|c|c|c|c|c|c|c|c|c|c|}
\hline $\begin{array}{c}\text { MOD. } \\
\text { DE } \\
\text { ENSINO }\end{array}$ & \multicolumn{10}{|c|}{ Ensino Regular } & \multirow{2}{*}{\multicolumn{2}{|c|}{$\begin{array}{l}\text { EJA } \\
\text { EJA }\end{array}$}} \\
\hline Nível & \multicolumn{4}{|c|}{ Educação Infantil } & \multicolumn{4}{|c|}{ Ens. Fundamental } & \multirow{2}{*}{\multicolumn{2}{|c|}{$\begin{array}{c}\text { Ens. Médio } \\
\text { Regular }\end{array}$}} & & \\
\hline Etapa & & & Pré- & cola & Anos & niciais & Anos & inais & & & Pres & acial \\
\hline Regime & Parc. & Integ & Parc. & Integ & Parc. & Integ. & Parc. & Integ. & Parc. & Integ & Fund & Méd. \\
\hline $\begin{array}{c}\text { Estadual } \\
\text { Urbana }\end{array}$ & 0 & 0 & 0 & 0 & 0 & 0 & 755 & 92 & 2.894 & 10 & 0 & 300 \\
\hline $\begin{array}{c}\text { Estadual } \\
\text { Rural }\end{array}$ & 0 & 0 & 0 & 0 & 0 & 0 & 0 & 0 & 0 & 0 & 0 & 0 \\
\hline $\begin{array}{l}\text { Mun. } \\
\text { Urbana }\end{array}$ & 0 & 258 & 713 & 0 & 827 & 1.139 & 1.131 & 399 & 0 & 0 & 412 & 0 \\
\hline $\begin{array}{l}\text { Mun. } \\
\text { Rural }\end{array}$ & 1 & 304 & 941 & 49 & 2.532 & 1.433 & 1.044 & 1.337 & 0 & 0 & 415 & 0 \\
\hline Total & 1 & 562 & 1.654 & 49 & 3.359 & 2.572 & 2.930 & 1.828 & 2.894 & 10 & 827 & 300 \\
\hline
\end{tabular}

Fonte: Censo Educacional MEC/INEP (2017). (Elaboração: Autores, 2018).

Observamos, a partir dos dados levantados, que o número de matrículas das escolas rurais, nos níveis de Educação Infantil e Ensino Fundamental, somam-se mais de sete mil e seiscentas (63,1\%), enquanto as da zona urbana registram pouco mais de quatro mil e quatrocentos $(36,9 \%)$ do total de matrículas nesses dois níveis (Pré-escolar e Ensino Fundamental). Por outro lado, no que se refere ao Ensino Médio, observamos que todas as matrículas se concentram na zona urbana. Isso porque, mesmo existindo os chamados "anexos" escolares, em alguns poucos povoados e alguns distritos do município, as matrículas são computadas como das escolas-sede, as quais estão todas situadas na sede do município. Aqui chegamos ao segundo aspecto levantado, concernente à comparação do número de escolas existentes na zona urbana e na zona rural, em seus diferentes níveis e sistemas de ensino. 
Quanto ao número de escolas existentes, há apenas quatro Escolas de nível médio. Todas são da rede Estadual de Educação da Bahia. Uma delas está situada no Distrito de Santana do Sobrado, sendo que, até o ano de 2016, assim como ocorre atualmente em outros povoados rurais, funcionava na forma de uma “extensão" das escolas da sede, em nível de Ensino Médio. Apenas em 2017, à referida extensão veio a ser instituída como outra unidade escolar de nível médio do sistema estadual de ensino (somando-se, atualmente, cinco escolas de nível médio). Já no que se refere às escolas do sistema municipal de ensino, existem, conforme o Censo escolar de 2017, 176 escolas municipais, sendo que 165 escolas (93,75\%) situam-se na zona rural, ou seja, são escolas do campo. E apenas onze escolas $(6,25 \%)$ são consideradas escolas urbanas.

Portanto, aqui esperamos ter chegado ao cerne da questão antes formulada. Entendemos, portanto, que o dito processo de disparidade ocorre, por um lado, pelo fato de os alunos serem forçados a se deslocarem, por não existirem escolas de nível médio no campo, para a sede do município. Por outro lado, existe o paulatino fechamento das escolas do campo, enquanto maioria absoluta das escolas municipais.

Devido à centralização das escolas, sobretudo de nível médio, os alunos do campo que residem nas comunidades mais distantes saem cedo de casa e chegam de volta à noite, passando horas dentro dos transportes escolares (que, aliás, não são nada confortáveis) e que se torna um tempo ocioso em suas vidas. Alguns desses alunos relataram-nos que chegam a sair, por exemplo, às nove horas (9h) da manhã, para assistir aula no turno vespertino, retornando para casa às vinte horas (20h) ou vinte e uma horas (21h). Esse exemplo, também, foi-nos dado por um dos professores entrevistados que nos informou o seguinte:

Nós temos um grande problema com relação ao transporte escolar aqui, porque a extensão do município é grande e tem aluno que sai de casa nove horas da manhã para chegar aqui doze e quarenta. Quando ele sai daqui cinco e meia, ele chega lá oito ou nove horas em casa. [...] Isso, aluno do fundamental. Porque nós temos aqui lugares próximos, próximos assim, se fosse à linha reta, mas o cara sai de uma localidade e passa em quatro, cinco, seis localidades recolhendo esses alunos para chegar à Casa Nova. Então, esse processo acaba sendo moroso. Exemplo: você anda oitenta quilômetros em um carro, é uma coisa, você anda, desenvolve mais. Agora você anda oitenta quilômetros dentro de um ônibus escolar que, de dez em dez minutos, ou de cinco em cinco minutos, ou de três em três quilômetros está parando. $\mathrm{Eu}$, no meu entender, esse aluno, quando chega aqui, já chega prejudicado. (Professor e Coordenador Técnico de Políticas da Secretaria de Educação, ENTREVISTA, 2018).

Diante de tal situação, muitos alunos acabam por desistir da escola. Sejam tanto pelos fatores da jornada do transporte quanto pela intensa rotina diária em ainda trabalhar na atividade agrícola. Essa situação reflete-se no aumento da chamada evasão escolar; outros, já na condição de jovens, entre a escolha de uma dura jornada de ida à escola ou em adentrar nas fazendas frutícolas em busca de trabalho, especialmente durante as safras (exportação), preferem esta àquela.

A referida disparidade do acesso escolar ao Ensino Fundamental para o Ensino médio ocorre de encontro à realidade econômico-social de exploração do agronegócio no município onde grande parte da população, explorada com sua força de trabalho nos latifúndios "modernos", tem a única 
alternativa para se viver. Assim é que se estabelece o cumprimento das definições de educação do Banco Mundial, aquelas em que não se almejam analfabetos, mas, sim, somente a execução de um nível mínimo de instrução para os trabalhadores que no caso da relação educação e agronegócio, ocorre muito mais em nível Fundamental.

O mencionado processo de formação mínima, evidenciado na relação educação e agronegócio, ocorre seja pela falta de acesso ou desistência dos níveis de ensino Fundamental e Médio, seja pelo próprio esvaziamento dos conteúdos escolares, uma vez que "os conteúdos são fundamentais e, sem conteúdos relevantes, conteúdos significativos, a aprendizagem deixa de existir, ela se transforma num arremedo, ela se transforma numa farsa." (SAVIANI, 1999, p. 66). O esvaziamento, portanto, é uma característica da atual educação escolar orientada-financiada pelo imperialismo e oferecida às classes dominadas.

O esvaziamento da educação escolar não compreende apenas os conteúdos. Compreende, também, a própria inexistência das escolas, devido ao intenso processo de fechamento, fundamentalmente, das escolas do campo. Esse processo foi desencadeado a partir da institucionalização da política de transporte escolar, ainda na década de 1990, e sua consequente transformação, não em uma política propriamente de educação, mas em uma política de transporte (negócio), cujos interesses privados se sobrepõem à educação pública.

Destaca-se ainda que, no processo de destruição das escolas do campo, entre 1995 e 2017, mais de 60 mil escolas foram fechadas, ou seja, significa que oito escolas são fechadas por dia no país. Tal realidade ganhou destaque, recentemente, sobretudo pela relação construída entre política e estética no projeto coletivo "Expedição Catástrofe: por uma arqueologia da ignorância", realizado por diversos artistas, urbanistas e designers brasileiros ${ }^{5}$. Esse projeto de expedição artístico-arqueológica, realizada nos três Estados com maior fechamento de escolas, respectivamente, Goiás, Minas Gerais e Bahia, denuncia que quase 10 mil, das 60 mil escolas fechadas, foram no Estado da Bahia.

De que maneira o município baiano de Casa Nova, terreno fértil do agronegócio frutícola, insere-se nesse contexto de fechamento das escolas do campo? Esta resposta está na relação educação e sociedade. O processo de fechamento das escolas do campo constitui-se de suma importância à nossa investigação. Esse processo resulta na principal implicação das políticas de educação no campo, a partir da relação ao agronegócio frutícola. Por isso, o abordaremos, mesmo sem esgotá-lo suficientemente.

O fechamento das escolas no referido Município tem sido um processo constante, no decorrer da última década, interligado diretamente com a disparidade de acesso das crianças e jovens à educação escolar em nível médio, concentrada na sede e nos principais distritos do município e ao avanço do latifúndio moderno, revestido de agronegócio frutícola. É um processo resultante das políticas de educação no campo, sobretudo de transporte escolar, desencadeadas desde a década de 1990 e que continua em curso até os dias atuais.

O Programa Nacional de Apoio ao Transporte Escolar (PNATE) e o Índice de Desenvolvimento da Educação Básica (IDEB) foram, especificamente, as políticas que mais contribuíram 
para o fechamento das escolas rurais. O PNATE com sua contribuição em montantes de dinheiro, e até mesmo veículos, para a condução das crianças e dos jovens até os distritos, povoados e mesmo à sede do município; o IDEB contribui pelo fato das escolas do campo ser sempre as que apresentam menores índices, o que faz com que seu fechamento seja considerado uma saída, causando a redistribuição dos alunos em escolas de melhores índices.

Com o crescente avanço do agronegócio frutícola, no entanto, o fechamento das escolas passa a ganhar, também, outro contorno: o de esvaziamento do campo, ao forçar os pais a se mudarem do campo até as cidades para que seus filhos estudem; alia-se com isso, a tentativa de encontrar trabalho no cenário verde dos latifúndios "modernos" e mecanizados.

Tanto a maioria das escolas, quanto das matrículas, estão concentradas nas instituições escolares situadas no campo e no âmbito da rede municipal de ensino. Com isso, o fechamento de escolas do campo se acentua ainda mais no município.

Tabela 2: Número de Escolas na Educação Básica - Casa Nova - BA (2010 a 2017)

\begin{tabular}{|c|c|c|c|c|c|c|c|c|c|}
\hline \multirow{3}{*}{ Ano } & \multicolumn{9}{|c|}{ Localização/Dependência Administrativa } \\
\hline & \multirow[b]{2}{*}{ Total $^{1-3 *}$} & \multicolumn{5}{|c|}{ Urbana } & \multicolumn{3}{|c|}{ Rural } \\
\hline & & Total & Estadual & Municipal & Privada & Total & Estadual & Municipal & Privada \\
\hline 2010 & 220 & 18 & 4 & 12 & 2 & 202 & - & 202 & - \\
\hline 2011 & 224 & 19 & 4 & 12 & 3 & 205 & - & 205 & - \\
\hline 2012 & 220 & 18 & 4 & 11 & 3 & 202 & - & 202 & - \\
\hline 2013 & 208 & 16 & 4 & 11 & 1 & 192 & - & 192 & - \\
\hline 2014 & 201 & 16 & 4 & 11 & 1 & 185 & - & 184 & 1 \\
\hline 2015 & 194 & 19 & 4 & 11 & 4 & 175 & - & 174 & 1 \\
\hline 2016 & 198 & 19 & 4 & 11 & 4 & 179 & - & 177 & 2 \\
\hline 2017 & 187 & 20 & 5 & 11 & 4 & 167 & - & 165 & 2 \\
\hline
\end{tabular}

*Total referente à soma dos três sistemas: estadual, municipal e privado.

Fonte: Censos Educacionais MEC/INEP (2010-2017). (Elaboração: Autores, 2018).

Atualmente, conforme o Censo Educacional de 2017, em Casa Nova - BA existem 176 escolas municipais, sendo apenas 11 escolas da sede (zona urbana). Para levantarmos o número de escolas do município, realizamos consulta aos arquivos do Censo Educacional (INEP/MEC) referente aos anos de $2010^{6}$ a 2017. Nos dados levantados (Tabela 2), observa-se que, em oito anos, houve uma redução de 18,31\% no número de escolas do campo. Foram 37 escolas fechadas no campo entre 2010 e 2017, contra apenas uma da zona urbana que, aliás, possui um número de escolas bem reduzido (11 escolas) em relação ao campo (165 escolas).

A maior parte das escolas do município (93,75\%), assim como o próprio número de matrículas $(63,1 \%)$, é de escolas rurais. Um município estruturalmente agrário. 
Gráfico 2: Turmas do Ensino Fundamental - (Casa Nova - BA, 2017)

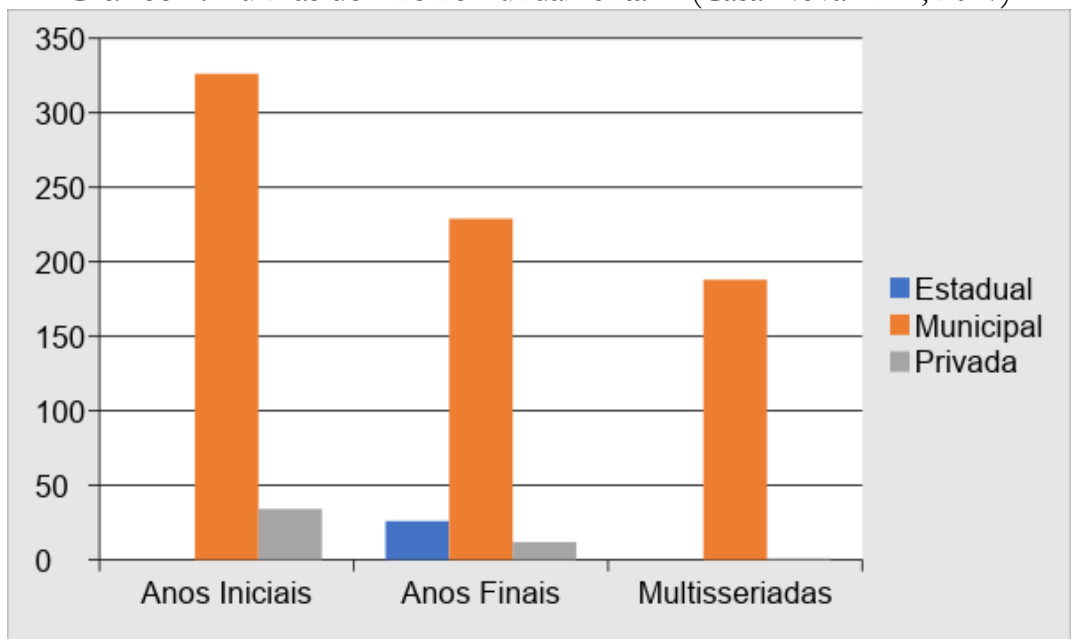

Fonte: Censo Educacional INEP/MEC (2017). (Elaboração: Autores, 2018).

O número de turmas multisseriadas, existentes no Município, no Ensino Fundamental é bastante significativo. Mais de 25\% das turmas de Ensino Fundamental do município são multisseriadas, todas, exclusivamente, no campo. São às escolas multisseriadas que se concentra o maior ataque de fechamento, imbuídos do discurso de sua ineficiência e má qualidade pedagógica, sem, no entanto, considerar suas reais condições de funcionamento.

Outro elemento que destacamos, a partir dos dados do Gráfico 2, é o predomínio da municipalização do Ensino Fundamental. A rede municipal responde por 91\% das turmas de Ensino Fundamental, contra 5,8 da rede privada e 3,2\% da rede estadual de ensino. Nesse sentido, o fechamento das escolas encontra-se, absolutamente, na rede municipal, por ser essa a responsável pelo Ensino Fundamental e pelas escolas/turmas multisseriadas.

O processo de fechamento das escolas do campo (rurais) no município em estudo é, portanto, contínuo e se acentuava no momento desta pesquisa. No ano de 2018 , dezenas de escolas estavam sendo fechadas no projeto de nucleação colocado pela prefeitura municipal. Em 2018, o prefeito anunciava tal projeto como sendo uma pauta de prioridade em sua efetivação. A fala em questão, colocada como parte do evento de abertura do ano letivo, foi noticiada por um blog da cidade de Petrolina com a seguinte notícia: "Casa Nova: jornada pedagógica reúne centenas de professores e prefeito renova compromisso de uma educação de qualidade". Para o prefeito, a educação de "qualidade", a qual o seu município ainda não conseguiu atingir, virá com a "nucleação" (leia-se, fechamento) das escolas do campo.

Todas as equipes das coordenações e direções sabem o quanto tenho me esforçado, plantando sementes e tenho certeza que iremos colber os frutos. Sementes importantes, a exemplo da nucleação das escolas, que vocês professores sabem da necessidade que é cada aluno estar na sua série. (WILKER TORRES apud WALDINEY PASSOS, 2018, grifo no original).

Fica explicito na fala do prefeito que a "necessidade" do processo se justifica apenas pelo fato de cada aluno não estar na sua série devida, por ser a maioria das escolas a serem fechadas, unidades de ensino multisseriadas, nas quais várias séries estão numa única turma (multisseriação) e sob a regência de um único professor (unidocência). 
Em geral, as classes de multisseriação funcionam no Brasil, segundo o próprio INEP, da seguinte maneira:

As classes multisseriadas têm alunos de diferentes séries e níveis em uma mesma sala de aula, independente do número de professores responsável pela classe. A unidocência ocorre quando um único professor é responsável pela condução do desenvolvimento de uma classe multisseriada. Embora possa acontecer de uma escola ou classe ser multisseriada e ter mais de um professor, as escolas multisseriadas do campo contam, na quase totalidade dos casos, com apenas um professor, o que torna unidocência e multisseriação termos equivalentes. (INEP, 2007, p. 25).

O processo de destruição, de fechamento das escolas multisseriadas no país, tal como sugere o prefeito, iniciou-se desde os anos de 1990, como forma de atender às orientações do imperialismo, na estratégia de esvaziar o campo para dar lugar ao latifúndio de novo tipo (agronegócio). Os argumentos, que partem, também, desde o próprio MEC, são de que a "nucleação" das escolas do campo é uma extrema necessidade, devido ao baixo nível de aprendizagem de seus alunos, pelos altos índices de repetência, evasão escolar e má qualidade dos professores, dentre várias outras argumentações.

De tal modo, as consequências, oriundas do modelo multisseriado, são justificadas por elas mesmas, desconsiderando-se, assim, as causas, as condições que favorecem tais consequências. Segundo ainda o próprio MEC, “os professores das escolas multisseriadas, além da atividade docente, acumulam outras tarefas administrativas voltadas para a manutenção da unidade escolar, chegando, na maioria das vezes, a ter que conciliar as atividades de limpeza com o preparo da merenda escolar." (INEP, 2007, p. 25). Nesse sistema, os professores não são apenas docentes, executores da prática pedagógica, mas assumem, junto com a atividade-fim, todas as atividades-meios da escola (gestão, coordenação, limpeza, merenda etc.).

Nesse sentido de entendimento, porém de forma antagônica ao anteriormente exposto, é possível reportarmos ao filme Ser e Ter (Être et avoir, de Nicolas Philibert, 2002)7, que aborda uma dessas escolas no interior da França e comprova a eficácia de sua proposta pedagógica. Se esse tipo de escola funciona em um país de economia capitalista desenvolvida, o problema não está em sua forma, mas nas condições pelas quais apenas resistem, bravamente, tais escolas. Dessa forma, “[...] o problema não é a sua organização, o fato de ser unidocente, de ser multisseriada, mas a falta de investimento na formação dos professores, nas condições materiais, no conteúdo das escolas etc.” (SOUZA, 2014, p. 164).

A já citada pesquisa do INEP (2007), sobre o “panorama da educação no campo”, admitia os reais, e principais, problemas das escolas multisseriadas:

\footnotetext{
Algumas experiências têm demonstrado que o problema das turmas multisseriadas está na ausência de uma capacitação especifica dos professores envolvidos, na falta de material pedagógico adequado e, principalmente, na ausência de uma infra-estrutura básica - material e de recursos humanos - que favoreça a atividade docente e garanta a efetividade do processo de ensino-aprendizagem. (INEP, 2007, p. 25-26).
}

No entanto, para os gestores municipais, ao encarnar o discurso e a cartilha de orientações do MEC/Banco Mundial, as escolas multisseriadas tornam-se um problema em si, apenas por considerar 
sua forma e, superficialmente, em consequência, sua incapacidade de uma significativa proposta pedagógica. Por tal justificativa, colocam a urgência na nucleação escolar, no argumento de que os alunos só aprenderão se estiverem nas suas respectivas séries escolares (seriação), consideradas como única situação provável de ensino-aprendizagem.

Um dos professores entrevistados, ao falar em nome da secretaria de educação, por sua dual condição de professor e coordenador técnico de políticas educacionais, afirmou o seguinte, sobre as escolas multisseriadas: "A maioria são multisseriadas. Nós fizemos aqui esse ano um trabalho de nucleação, tentando diminuir a quantidade de escolas multisseriadas." Assim, ao ser perguntado se essas escolas multisseriadas eram um problema para a rede municipal de ensino, o mesmo professor respondeu:

É um problema porque você dar aula para quarenta alunos de uma turma é uma coisa. Você dar aula de vinte, dez, doze, quinze alunos de seis [séries]... Porque, antigamente, era quatro: primeira, segunda, terceira e quarta série. Hoje, com a política de quatro anos, entra o pré-escolar. Aí fica: pré-escolar, primeiro, segundo, terceiro, quarto e quinto ano um professor só. Tudo dentro de uma única sala de aula. A secretaria esse ano fez um projeto de nucleação. Ela conseguiu fechar, nós estamos brigando ainda e tal, mas nós conseguimos fechar quase sessenta. (Membro da Secretaria Municipal de Educação, ENTREVISTA, 2018)

No discurso da incapacidade pedagógica, pauta-se o referido projeto de nucleação escolar em Casa Nova - BA. O mesmo está sendo acompanhado por diversas instituições e entidades que, inclusive, o denunciam como crime deliberado que vem sendo realizado, paulatinamente, no decorrer dos últimos anos. Exemplo disso é a nota publicada pelo Movimento dos Atingidos por Barragens (MAB), intitulada "Fechar Escolas é crime! Em defesa dos direitos dos atingidos (as) de Sobradinho de estudar, dizemos não a nucleação!". Nessa nota, o MAB afirma que a precarização das escolas de Casa Nova é conhecida, há mais de uma década, pelos órgãos de fiscalização (CGU e Ministério Público). No entanto, nunca tomaram nenhuma medida de punição ao município.

desde de 2005 a Controladoria Geral da União (CGU) em seus relatórios de fiscalização tem apontado que as escolas rurais no município de Casa Nova na Bahia, estão em condições estruturais inadequadas para seu funcionamento. Ao fim de 2017 o Ministério Público Estadual exigiu que a Prefeitura tomasse providencias imediatas sobre pena de punições. (MOVIMENTO DOS ATINGIDOS POR BARRAGENS, 2018).

A partir das "pressões" recebidas, tanto da CGU quanto do Ministério Público, a prefeitura e a Secretaria de Educação iniciaram a nucleação escolar, talvez como estratégia de se eximir da falta de infraestrutura mínima adequada (banheiro e cantina) nas escolas multisseriadas. A referida realidade foi admitida pela Secretaria de Educação que argumenta ser culpa, não da falta de infraestrutura básica e de condições pedagógicas, mas da incapacidade pedagógica-educacional da forma escolar multisseriada, entendida como retrógrada e ultrapassada.

Nas entrevistas concedidas, é sempre ressaltada a falta de estrutura das escolas e as suas condições degradantes, na concepção de que as crianças podem (ou devem) fazer suas atividades fisiológicas fora do prédio escolar, em céu-aberto. 
A questão da nucleação, talvez não tenha dado $100 \%$ certo, porque tinha muitas escolas que os prefeitos antigos construíam, mas eles achavam que os meninos não tinha que ter lugar para fazer xixi, tinha que fazer no matinho, entendeu? E aí foi melhorando, melhorando, mas acredito que com essa nova nucleação, com essa nova visão dessa nova gestão... eles estão construindo banheiro, masculino e feminino, e a cantina. Essas escolas que estão recebendo banheiro e cantina vão receber os alunos daquelas escolas que não tinham essa infraestrutura. (Membro da Secretaria Municipal de Educação, ENTREVISTA, 2018).

$\mathrm{Na}$ realidade descrita na entrevista, a realização de qualquer prática pedagógica significativa se torna praticamente impossível. Torna-se, então, muito fácil a construção de uma retórica discursiva que aponte o atraso da escola multisseriada, apenas por sua forma múltipla e pela sobrecarga do trabalho pedagógico unidocente. No entanto, qual escola, mesmo as seriadas, conseguiria êxito na aprendizagem educacional dos seus alunos a partir das referidas condições estruturais degradantes? A resposta não parece difícil, senão óbvia.

Para tanto, devemos levar em consideração, além das referidas faltas estruturais, o fato de que os professores dessas escolas multisseriadas, em sua grande maioria, não possuem nível superior e não recebem formação pedagógica adequada. Também inexistem no município pesquisado, políticas de currículo, de avaliação e de formação continuada para os professores. Além disso, o processo de condução e recondução dos gestores escolares é por indicação, por nomeação e, por isso, muitos gestores escolares não são efetivos do sistema municipal de ensino. Cerca de dois terços dos professores municipais são contratados e oriundos de indicação política, conforme nos foi informado pela Secretaria de Educação.

Prevalece, assim, em tal cenário, as práticas clientelísticas, de favoritismo, de servilismo, típicas do gamonalismo, que no Brasil convencionamos chamar de coronelismo. A partir da realidade peruana, Mariátegui (2010, p. 54) afirma que o gamonalismo (coronelismo) "compreende uma grande hierarquia de funcionários, intermediários, agentes, parasitas etc.” e não apenas como designação dos grandes proprietários latifundiários e seu poder político-econômico e social, mas, ao contrário, uma teia hierárquica e vertical de poder.

No caso da educação, a ação dos grandes proprietários de terra é indireta. Os agentes indiretos são os seus subordinados nos setores da administração pública. Professores ocupando cargos técnicos nas instituições dirigentes da educação se transformam em opressores de sua própria classe porque se colocam a serviço dos interesses do grupo detentor do poder. (SOUZA, 2014, p. 235).

No contexto de predomínio das práticas do gamonalismo, a prefeitura decidia pela nucleação escolar. A decisão se dá a partir das "pressões" externas recebidas, continuamente, há mais de dez anos pelos órgãos "fiscalizadores” da educação (CGU, Ministério Público etc.), que fiscalizam de acordo com os "padrões” requeridos pelo MEC. Na precariedade de um sistema de ensino repleto de práticas gamonais, invés da manutenção e readequação mínima dos prédios escolares, torna-se a nucleação (fechamento), a saída mais fácil, a mais viável, a qual é reduzida a uma suposta incompetência pedagógica.

Com o processo de nucleação, de constante fechamento das escolas do campo, aumentam-se as despesas com o transporte escolar, em níveis até superiores aos dispêndios de conjunto da própria prática pedagógica. "O transporte escolar passou a fazer parte da agenda educacional e se gasta muito mais 
com esse elemento de despesa que com as demandas de cunho pedagógico, formação de professores, valorização do magistério, melhoria das condições de trabalho etc." (SOUZA, 2014, p.165-6). Premissa constatada pela autora no Norte do país, especificamente, em diversos municípios rondonienses, e que se aplica, como veremos, ao município de Casa Nova - BA, no sertão do Vale do São Francisco.

No município de Casa Nova - BA, pois, as rotas de transporte escolar são enormes e ainda aumentaram, segundo a Secretaria de Educação, após a referida nucleação, que ainda está em curso. Segundo esclarece o professor e coordenador técnico de políticas, a prefeitura assume um alto custo com o transporte escolar:

Infelizmente, o recurso que vem do PNATE não é 30\% do que a prefeitura gasta. Hoje nós temos aqui, mais ou menos, cento e vinte e poucas rotas de transporte escolar, entre ônibus, van, micro-ônibus, carro pequeno. Para você ter uma ideia, ano passado nós recebemos trezentos mil por ano. A Prefeitura gastava oitocentos, novecentos mil por mês. (Professor e Coordenador Técnico de Políticas da Secretaria de Educação, ENTREVISTA, 2018).

A partir de tal constatação, sobre o alto custo do transporte escolar, perguntamos ao entrevistado quais os recursos, então, que complementavam os referidos gastos, já que o PNATE, enquanto programa financiador do transporte escolar, não financiava um terço dos dispêndios. Assim se pronunciou: "são recursos do FUNDEB-quarenta. A prefeitura pega uma parte do FUNDEB-quarenta para o transporte escolar. O restante que falta. O grande restante".

Os recursos do FUNDEB devem ser empregados, segundo as suas diretrizes orçamentárias, exclusivamente, em ações de manutenção e de desenvolvimento da educação básica pública, especialmente, na valorização do magistério. Segundo o manual de orientação do FUNDEB, “[...] a parcela mínima de 60\% do Fundo deve ser destinada à remuneração dos profissionais do magistério em efetivo exercício na educação básica pública”. (BRASIL, 2009, p. 19). Já “[...] os recursos restantes (de até $40 \%$ do total) devem ser direcionados para despesas diversas consideradas como de Manutenção e Desenvolvimento do Ensino (MDE), realizadas na educação básica, na forma prevista no artigo 70 da Lei no 9.394/96 (LDB)". (BRASIL, 2009, p. 21).

É do percentual referente aos $40 \%$, destinado a outras despesas, que a prefeitura custeia os seus altos valores de transporte escolar, em detrimento do aperfeiçoamento do sistema de ensino como, por exemplo, criação de políticas de formação inicial e continuada de professores, políticas de currículo, de avaliação etc. aspectos estes ausentes no referido sistema de ensino municipal. No entanto, estas questões não são vistas como prioridades. Os discursos apontam para o fato de que o "grande problema" são as escolas multisseriadas, sua "ineficácia” pedagógica e educacional.

A pesquisa revelou, portanto, uma catástrofe local em meio uma catástrofe nacional: em um período de 20 anos no Brasil se registrou fechamento de uma média de 8 escolas públicas rurais por dia. Esse é o dado apontado, por exemplo, pelo projeto "Expedição catástrofe: por uma arqueologia da ignorância", com base também nos dados do Censo Educacional (MEC), que registrou o fechamento de 60.065 escolas rurais no período de 1995 a 2016. O referido projeto, realizado de 2015 a 2018, se 
desdobrou em três expedições adentradas no interior do Brasil, nos três estados mais afetados pelo fechamento de escolas: Bahia, Minas Gerais e Goiás. Além de viagens para realização de pesquisas de campo, produção de imagens e visita as escolas fechadas nos três estados, o projeto realizou uma "Torre de Transmissão" para leitura dos nomes das milhares de escolas fechadas.

Assim como no referido projeto, nossa contribuição reside em compreender o fechamento das escolas do campo, mesmo que nos limites do município de Casa Nova - BA, como uma consequência direta das políticas educacionais em âmbito nacional. São políticas catastróficas, pois são gestadas na orientação e interesses do capital financeiro internacional, notadamente alinhadas ao setor produtivo que, no campo, se convenciona chamar de agronegócio. As escolas são fechadas, o campo esvaziado e as fronteiras agrícolas são ampliadas para os interesses desse setor latifundiário.

Portanto, a política de fechamento das escolas do campo, no município baiano de Casa Nova, é um processo permanente, paulatino e que possui diversos dobramentos, interesses e graves consequências, sobretudo, a quem vive e trabalha no campo.

Consideramos, entretanto, que as análises aqui realizadas não se esgotam na complexidade de tal processo, o qual necessita ser estudado mais a fundo, tanto em uma maior dimensão de seus desdobramentos quanto em um alargamento em termos de delimitação geográfica, no que concerne, não apenas ao município em estudo, mas aos demais municípios do polo de produção agrícola Juazeiro/Petrolina.

\section{Considerações finais}

A política imperialista liderada pelos Estados Unidos a partir da Segunda Guerra Mundial (1939-1945) levou à hegemonia desse país sobre os demais países latino-americanos, particularmente o Brasil. A hegemonia americana fortaleceu-se com a instituição de organismos controlados pelo capital financeiro internacional, a exemplo do Banco Mundial, articulador e financiador de políticas na área da educação, objetivando ajustar o ensino aos interesses do capital.

A partir da década de 1990, no cenário da profunda e permanente crise capitalista, a educação passou a ser assumida nas agendas dos órgãos do imperialismo. Com as suas "estratégias" de educação, o imperialismo passou a intervir diretamente nas políticas educacionais, tanto no financiamento, quanto na orientação de políticas e programas a serem implementados nos países dominados. Os reflexos dessa intervenção recaíram sobre a educação básica, trazendo mudanças notáveis no gerenciamento das políticas voltadas para esse nível de ensino, como a descentralização da gestão, a busca de parcerias privadas para o financiamento das escolas e a valorização do aspecto quantitativo das avaliações com ênfase nos resultados mensurados por parâmetros externos.

Desde então, as políticas educacionais, gestadas no âmbito do governo brasileiro, passaram a ser pautadas na lógica do capital financeiro. O FUNDEF que vigorou de 1998 a 2006, bem como o FUNDEB que o substituiu a partir de 2007, são exemplos de políticas que visam racionalizar os recursos 
da educação e tornar a aplicação desses recursos mais eficiente, porém com implicações negativas para a educação básica.

No campo, as implicações das políticas educacionais foram (e continuam sendo) bem maiores. As escolas multisseriadas, erguidas na maioria das vezes sem estrutura adequada, foram sendo fechadas, paulatinamente, até os dias atuais. Em detrimento, a política de transporte escolar ganhou forma mercadológica e o Ensino Médio foi centralizado, passando a ser gerenciado, apenas, pelos sistemas estaduais.

O fechamento das escolas rurais em Casa Nova - Bahia, configura-se como uma das maiores implicações à formação escolar dos jovens do campo. Ao passo que esse processo se alarga, aumenta-se a disparidade de acesso e permanência dos filhos dos camponeses na escola. Muitos alunos não concluem o Ensino Fundamental e outros tantos, em número bem maior, não chegam a ingressar no Ensino Médio.

De tal maneira, vão se concretizando as orientações de educação preconizadas pelo imperialismo, ao passo que vão sendo ajustadas aos interesses dos grupos dominantes locais a partir de uma escola no campo sem estrutura e sem condições mínimas para oportunizar o acesso ao conhecimento dos trabalhadores e os seus filhos. As escolas vão sendo fechadas enquanto o latifúndio, na sua face de agronegócio, vai expandindo as suas fronteiras. Nesse contexto, os trabalhadores e os seus filhos, mesmo que ainda muito jovens, são absorvidos e explorados na engrenagem "moderna" desse latifúndio de novo tipo.

Nesse sentido, as implicações das políticas de educação no campo, oriundas do imperialismo e suas agências (a exemplo do Banco Mundial), na formação escolar básica dos jovens alunostrabalhadores do agronegócio frutícola, ocorre, sobretudo, devido ao esvaziamento dos conteúdos da educação escolar básica. Esse esvaziamento é causado a partir de um currículo escolar pautado nas pedagogias pós-modernas do lema "aprender a aprender", que são ecléticas, pragmáticas e pautam neotecnicismo pedagógico, acarretando uma formação mínima dos sujeitos, conforme requer o agronegócio.

Há uma superexploração da força de trabalho dos jovens do campo, realizada pelas fazendas do agronegócio frutícola. Esse que se entende como um latifúndio de novo tipo, uma nova face da grande propriedade agrária latifundiária. Isso porque, mesmo propagando a ideia da agroindústria, ou seja, da modernização da agricultura, tornando o campo produtivo, de constante inovação tecnológica, por outro lado, as relações de trabalho continuam precarizadas e de extremo peso de exploração para os trabalhadores.

Por fim, a educação brasileira, ao submeter-se aos ditames do capital internacional, adotou práticas políticas e sociais articuladas entre o Estado e o setor produtivo, notadamente o agronegócio. Tais práticas culminam numa concepção de educação que, no campo, encontra-se profundamente atravessada pelas relações de classe.

\section{Referências:}


BANCO MUNDIAL. Prioridades y estrategias para la educación: examen del Banco Mundial. Washington: DC/Banco Mundial, 1996. (El desarrollo en la práctica). 218p.

BANCO MUNDIAL. Estrategia sectorial de educación: Grupo del Banco Mundial, Red sobre Desarrollo Humano. Washington, DC/Banco Mundial, 2000.

BANCO MUNDIAL. Atingindo uma Educação de Nível Mundial no Brasil: próximos passos sumário executivo. 2010. Disponível em: <http://cenpec.org.br/biblioteca/educacao/estudos-epesquisas/achieving-world-class-education-in-brazil-the-next-agenda>. Acesso em: 10 abr. 2017.

BRASIL. FNDE recebe missão do Banco Mundial. Fundo Nacional de Desenvolvimento da Educação, Ministério da Educação - MEC. 2007. Disponível em: <http://www.fnde.gov.br/acesso-ainformacao/institucional/area-de-imprensa/noticias/item/1314-fnde-recebe-miss \%C3\%A3o-do-bancomundial>. Acesso em: 22 jun. 2017.

BRASIL. Ministério da Integração Nacional. Região Integrada de Desenvolvimento - RIDE Petrolina-Juazeiro. 19 de maio de 2015. < http://www.mi.gov.br/regiao-integrada-de-desenvolvimentodo-polo-petrolina-e-juazeiro>. Acesso em: 19 jun. 2017.

BRASIL. LEI No 9.394, de 20 de dezembro de 1996. Estabelece as diretrizes e bases da educação nacional. Presidência da República. Casa Civil: Subchefia para Assuntos Jurídicos. Brasília, 20 dez. 1996.

BRASIL. LEI N N $^{\circ} 424$ de 24 de dezembro de 1996. Dispõe sobre o Fundo de Manutenção e Desenvolvimento do Ensino Fundamental e de Valorização do Magistério. Presidência da República. Casa Civil: Subchefia para Assuntos Jurídicos. Brasília, 24 dez. 1996.

BRASIL. FUNDEB - Manual de orientação. Fundo Nacional de Desenvolvimento da Educação, Ministério da Educação - MEC. 2009. Disponível em:

<ftp://ftp.fnde.gov.br/web/fundeb/manual_orientacao_fundeb.pdf>. Acesso em: 11 abr. 2018.

GIL, A. C. Como elaborar projetos de pesquisa. 4 ed. São Paulo: Atlas, 2002.

INSTITUTO BRASILEIRO DE GEOGRAFIA E ESTATÍSTICA - IBGE. Censo Agropecuário 2006: Brasil, Grandes Regiões e Unidades da Federação. Rio de Janeiro: IBGE, 2009.

INSTITUTO BRASILEIRO DE GEOGRAFIA E ESTATÍSTICA - IBGE. Censo agropecuário: resultados preliminares. Brasília, 2006.

INSTITUTO BRASILEIRO DE GEOGRAFIA E ESTATÍSTICA - IBGE. Censo demográfico 2010. Disponível em: <https://cidades.ibge.gov.br/>. Acesso em: 22 jun. 2017.

INSTITUTO NACIONAL DE ESTUDOS E PESQUISAS EDUCACIONAIS ANÍSIO TEIXEIRA INEP. Panorama da Educação do Campo. Brasília: INEP, 2007.

INSTITUTO NACIONAL DE ESTUDOS E PESQUISAS EDUCACIONAIS ANÍSIO TEIXEIRA INEP. Sinopse Estatística da Educação Básica (2010 a 2017). Brasília: INEP, 2018. Disponível em: <http://inep.gov.br/web/guest/sinopses-estatisticas-da-educacao-basica>. Acesso em: 22 abr. 2018.

JESUS, A. C.; BEZERRA, M. C. S. A herança colonial e as implicações na educação do campo no Brasil. Rev. HISTEDBR On-line, Campinas, n. 50 (especial), 2013. p. 238-250.

JUNQUEIRA, V. H. Educação, trabalho e ideologia: análise da relação agronegócio e educação na região de Ribeirão Preto - SP. 2014. 212 f, Dissertação (Mestrado em Educação). Universidade Federal de São Carlos, São Carlos. 2014.

JUNQUEIRA, V. H. A quem interessa a educação dos trabalhadores do campo? Uma análise do PRONACAMPO. Rev. Exitus. Santarém-PA, v. 5, n. 2, p. 83-100, Jul./Dez. 2015.

MARIÁTEGUI, José Carlos. Sete ensaios de interpretação da realidade peruana. 2. ed. São Paulo: Expressão Popular, 2010.

MOVIMENTO DOS ATINGIDOS POR BARRAGENS (MAB). Fechar Escolas é crime! Em defesa dos direitos dos atingidos(as) de Sobradinho de estudar, dizemos não a nucleação! 22 fev. 2018.

Disponível em: < http://www.mabnacional.org.br/noticia/fechar-escolas-crime> . Acesso em: 10 abr. 2018. 
MOTA JUNIOR, W. P.; MAUÉS, O. C. O Banco Mundial e as Políticas Educacionais Brasileiras. Educação \& Realidade, v. 39, n. 4, Out./Dez., 2014, pp. 1137-1152.

PASSOS, Waldiney. Casa Nova: jornada pedagógica reúne centenas de professores e prefeito renova compromisso de uma educação de qualidade. Blog. 18 de Fevereiro de 2018. Disponível em: $<$ http://www.waldineypassos.com.br/casa-nova-jornada-pedagogica-reune-centenas-de-professores-eprefeito-renova-compromisso-de-uma-educacao-de-qualidade/>. Acesso em: 22 abr. 2018.

PEREIRA, J. M. M. Poder, política e dinheiro: a trajetória do Banco Mundial entre 1980 e 2013. In: PEREIRA, J. M. M.; PRONKO, M. (Org.). A demolição de direitos: um exame das políticas do Banco Mundial para a educação e a saúde (1980-2013). Rio de Janeiro: Escola Politécnica de Saúde Joaquim Venâncio, 2014. p.19-63.

SAVIANI, D. Escola e democracia: teorias da educação, curvatura da vara, onze teses sobre educação e política. 32 ed. Campinas, SP: Autores Associados, 1999.

SOUZA, M. M. Imperialismo e educação do campo. Araraquara: Cultura Acadêmica, 2014.

TAFFAREL, C. Z.; MUNARIM, A. Pátria educadora e fechamento de escolas do campo: o crime continua. Revista Pedagógica, Chapecó, v. 17, n. 35, p. 41-51, maio/ago. 2015.

\footnotetext{
Notas

${ }^{1}$ Mestre em Educação pelo Programa de Pós-Graduação em Formação de Professores e Práticas Interdisciplinares (PPGFPPI), Universidade de Pernambuco - UPE Campus Petrolina. Graduado em História pela mesma instituição e Pedagogia pela Faculdade de Educação Superior de Pernambuco (FAESPE). Atualmente é Professor da educação básica, atuando como Coordenador Pedagógico do Município de Petrolina/PE. É integrante do Grupo de Pesquisa História e Memória (UPE). Currículo Lattes: http://lattes.cnpq.br/5476667900651035. Orcid: http://orcid.org/0000-0002-4356-2914. E-mail: francielupe@gmail.com.

2 Doutora em Educação pela Universidade Federal do Ceará (UFC). Atualmente é professora adjunta do Colegiado de Nutrição da Universidade de Pernambuco (UPE), Campus Petrolina. Atua como professora permanente do Programa de Pós-graduação em Formação de Professores e Práticas Interdisciplinas (PPGFPPI) da UPE. Integrante do Grupo de Pesquisa em História e Educação do Sertão do São Francisco (GEPHESF) e do grupo de Pesquisa História e Memória (UPE). Currículo Lattes: http://lattes.cnpq.br/5169954250280873. Orcid: http://orcid.org/0000-0001-5655-1184. E-mail: maria.leite@upe.br.

3 Original: "La educación primaria y secundaria es cada vez más importante: en los ejercicios de 1990 a 1994 le correspondió la mitad de todos los préstamos para educación".

${ }^{4} \mathrm{O}$ município de Casa Nova - BA possui a maior extensão territorial, dentre os que integram o polo Juazeiro/Petrolina da fruticultura, com uma área de $9.647,069 \mathrm{~km}^{2}$ e densidade $6,73 \mathrm{hab} / \mathrm{km}^{2}$. (IBGE, 2010).

${ }^{5}$ Para outras informações do projeto, ver: <https://expedicaocatastrofeblog.wordpress.com/>.

${ }^{6}$ O censo Educacional começou a ser informatizado a partir de 2007. Porém, nos anos de 2007 a 2009 não havia a informatização dos dados por município, apenas pelas Regiões do país e seus respectivos Estados.

7 O personagem central da trama é Georges Lopez, professor de uma escola multisseriada (alunos numa faixa etária entre 3 e 12 anos) do vilarejo de St. Etienne-sur-Usson, em uma região montanhosa do Maciço Central, no interior da França. Ele prepara, sozinho, cada criança para o ingresso no ensino médio (o que no Brasil corresponde ao Fundamental II), ensinando-os não somente a ler, a escrever e a calcular, mas também a conviver com as diferenças, a cooperarem entre si e, acima de tudo, a raciocinar, a pensar e a agir por si próprio.
}

Recebido em: 23 de fevereiro de 2021

Aprovado em: 12 de abril de 2021 